\title{
ANALISIS LAYANAN FISIOTERAPI DALAM UPAYA PELAYANAN KESEHATAN DI PUSKESMAS WILAYAH DKI JAKARTA
}

\author{
Putri Karina Syafitri ${ }^{1)}$, Vetty Yulianty Permanasari ${ }^{2)}$ \\ ${ }_{1}^{, 2}$ Universitas Indonesia, Depok \\ Fakultas Kesehatan Masyarakat Universitas Indonesia \\ Kampus Baru UI Depok 16424, Indonesia \\ pkarinas58@gmail.com
}

\begin{abstract}
Background:The increase in NCD's such as hypertension, stroke, diabetes mellitus, joint disease, lack of physical activity, injury, and disability in line with the increasing need for physiotherapy services in health facilities including in Community Health Centers. The role of physiotherapist in the Community Health Centers according to Permenkes No. 65 of 2015 is to carry out activities in the form of promotive and preventive without prejudice to curative and rehabilitative. The purpose of this study is to analyze physiotherapy services at the Community Health Centers using a system approach seen through 5 levels prevention measures namely are health promotion, specific protection, early diagnosis and prompt treatment, disability limitation and rehabilitation efforts at 6 Puskesmas in DKI Jakarta. This study uses qualitative research methods through a phenomenological approach. The results of this study obtained a depthoverview of the efforts of health services at the Physiotherapy Services, namely the provision of medical services is preferred over promotive and preventive efforts. Physiotherapy services at the Puskesmas have been regulated in the Decree of the Puskesmas Head by referring to Permenkes No. 75 of 2014. Public health activities in collaboration with the Physiotherapy Services at the Puskesmas are only carried out by 3 Puskesmas and some of them only conduct individual services. This study recommends that adding 1 physiotherapist HR to be able help physiotherapy services outside the building and physiotherapy organizations can create specialized public health training to support physiotherapy competencies.
\end{abstract}

Keywords: Community Health Centers, Physiotherapy services, Five levels prevention

\begin{abstract}
Abstrak
Latar belakang : Meningkatnya penyakit tidak menular seperti hipertensi, stroke, diabetes melitus, penyakit sendi, aktivitas fisik kurang, cedera, dan disabilitas sejalan dengan peningkatan kebutuhan masyarakat akan layanan fisioterapi di sarana kesehatan termasuk Puskesmas. Peran dan fungsi fisioterapis di Puskesmas menurut Permenkes No. 65 tahun 2015 yaitu melakukan kegiatan berupa promotif dan preventif tanpa mengesampingkan kuratif dan rehabilitatif. Tujuan : dari penelitian ini yaitu menganalisis layanan fisioterapi di Puskesmas menggunakan pendekatan sistem dilihat melalui lima tingkatan upaya preventif yaitu health promotion, spesific protection, early diagnosis and prompt treatment, disability limitation dan rehabilitation di enam Puskesmas wilayah DKI Jakarta. Metode penelitian : Penelitian ini menggunakan metode penelitian kualitatif melalui pendekatan fenomenologi. Hasil : dari penelitian ini didapatkan gambaran mendalam mengenai upaya pelayanan kesehatan pada layanan fisioterapi di Puskesmas yaitu pemberian pelayanan pengobatan lebih diutamakan dibandingkan upaya promotif dan preventif. Pelayanan fisioterapi di Puskesmas sudah diatur dalam SK Kepala Puskesmas dengan mengacu pada Permenkes No. 75 tahun 2014. Kegiatan kesehatan masyarakat yang bekerjasama dengan layanan fisioterapi di Puskesmas hanya dilakukan oleh 3 Puskesmas dan sebagiannya hanya melakukan pelayanan perseorangan saja. Penelitian ini merekomendasikan agar menambahkan 1 (satu) SDM Fisioterapis lagi agar dapat membantu pelayanan fisioterapi di luar gedung dan organisasi fisioterapi dapat membuat pelatihan khusus kesehatan masyarakat untuk mendukung kompetensi fisioterapi.
\end{abstract}

Kata kunci : Layanan Fisioterapi, Puskesmas, Lima Tingkatan Upaya Preventif 


\section{Pendahuluan}

Puskesmas merupakan fasilitas kesehatan tingkat pertama yang merupakan ujung tombak penyelenggaraan pelayanan kesehatan tingkat dasar di tingkat masyarakat. (1) Berdasarkan Riskesdas tahun 2018 didapatkan adanya peningkatan penyakit tidak menular seperti hipertensi, penyakit sendi, stroke, diabetes melitus, aktivitas fisik kurang, cedera, dan disabilitas.

Peningkatan penyakit tidak menular yang paling banyak didapati pada penduduk usia diatas 65 tahun seperti hipertensi dari $25.8 \%$ meningkat menjadi $34.1 \%$ dan stroke dari 7 per mil menjadi 10.9 per mil. Tidak hanya menyerang penduduk usia lanjut, diabetes mellitus pada penduduk usia diatas 15 tahun meningkat dari $6.9 \%$ menjadi $8.5 \%$. selain itu adanya peningkatan prevalensi penyakit sendi pada penduduk diatas usia 15 tahun yaitu sebesar 7.3\%, hal ini didukung oleh peningkatan aktivitas fisik kurang pada penduduk usia diatas 10 tahun dari $26.1 \%$ menjadi $33.5 \%$. Selain itu cedera yang menggangu kegiatan sehari-hari mengalami peningkatan dari $8.2 \%$ menjadi $9.2 \%$ dan untuk rata-rata disabilitas pada anak usia 5-17 tahun meningkat sebesar 3.4\% dan usia dewasa 18 - 59 tahun meningkat menjadi $23.08 \%$. (2)

Keberadaan layanan fisioterapi di Puskesmas merupakan upaya pembaharuan dalam menunjang upaya kesehatan masyarakat maupun perorangan, serta sebagai agen perubahan sehingga individu, keluarga dan/atau kelompok masyarakat menjadi lebih sehat, bugar dan produktif. Dengan mengintegrasikan fisioterapis ke dalam tenaga kesehatan di Puskesmas diidentifikasi dapat meningkatkan kualitas pelayanan, serta adanya layanan fisioterapi di Puskesmas memiliki peranan terutama pada tingkat promotif dan preventif serta akses langsung pada kuratif dan rehabilitatif. (3)

Peran dan fungsi fisioterapi di Puskesmas menurut Permenkes Nomor 65 tahun 2015 yaitu melakukan kegiatan berupa promotif dan preventif termasuk skrining dan/atau deteksi dini. Upaya promotif yang dilakukan layanan fisioterapi untuk meningkatkan derajat kesehatan masyarakat berupa memelihara dan meningkatkan gerak dan fungsi tubuh dengan sasaran layanan adalah orang yang sehat agar tidak terkena penyakit. Sedangkan upaya preventif yang dilakukan layanan fisioterapi yaitu pencegahan terhadap gangguan gerak serta keterbatasan fungsi, ketidakmampuan individu yang berpotensi untuk mengalami gangguan gerak dan fungsi tubuh akibat faktor kesehatan, sosial ekonomi maupun gaya hidup salah satunya yaitu dengan memberikan penyuluhan, pengobatan dan pemulihan untuk mengurangi keluhan nyeri, dan melakukan program untuk meningkatkan fleksibilitas tubuh, daya tahan atau kebugaran, serta keselarasan postur dalam aktivitas sehari-hari.(4)

Meskipun diketahui bahwa pada saat ini pemahaman dan kesadaran masyarakat terhadap pentingnya peran pelayanan Fisioterapi di masyarakat masih rendah.(5) namun menurut hasil penelitian Black, Ingman, \& Janes (2016) mengenai peran Fisioterapis dalam upaya promosi kesehatan fisioterapis mampu memberikan upaya aktivitas fisik sebesar (91.3\%), menjaga berat badan yang sehat $(73 \%)$, dan upaya tindakan berhenti merokok $(51.3 \%)$. (6)
Berdasarkan studi pendahuluan didapatkan hanya $2 \%$ atau terdapat 6 (enam) Puskesmas yang memiliki pelayanan fisioterapi dari total 340 Puskesmas di wilayah DKI Jakarta. Disamping itu diketahui bahwa belum adanya kebijakan yang mendukung terkait pelayanan fisioterapi di Puskesmas mengakibatkan sebagian besar upaya kesehatan yang dilakukan layanan fisioterapi hanya memberikan pelayanan perseorangan yaitu dominan upaya kuratif dan rehabilitatif. Hal tersebut belum sesuai dengan peran dan fungsi fisioterapi di Puskesmas yaitu memberikan layanan promotif dan preventif di masyarakat.

Berdasarkan latar belakang diatas peneliti mengangkat masalah ini untuk menganalisis gambaran layanan fisioterapi di Puskesmas melalui lima tingkatan upaya preventif yaitu health promotion, upaya spesific protection, upaya early diagnosis and prompt treatment, upaya disability limitation dan upaya rehabilitation di enam Puskesmas wilayah DKI Jakarta.

\section{Metode}

Penelitian ini menggunakan metode penelitian kualitatif melalui pendekatan fenomenologi yang bertujuan untuk mendapatkan gambaran mendalam dari peran layanan Fisioterapi di Puskesmas wilayah DKI Jakarta sesuai dengan pengalaman yang dialami. Pengambilan data dilakukan pada bulan Juli hingga September tahun 2019 di 6 (enam) Puskesmas di wilayah DKI Jakarta yang memiliki pelayanan Fisioterapi, antara lain Puskesmas Kecamatan Matraman, Puskesmas Kecamatan Jatinegara, Puskesmas Kecamatan Koja, Puskesmas Kecamatan Kebayoran Lama, Puskesmas Kecamatan Pasar Minggu dan Puskesmas Kecamatan Pancoran. Enam Puskesmas tersebut dipilih dengan dasar yaitu Puskesmas yang berada di Provinsi DKI Jakarta yang memiliki pelayanan Fisioterapi.

Pengumpulan data primer didapatkan dari hasil wawancara mendalam didapatkan melalui sumber yaitu seluruh tenaga fisioterapis di Puskesmas dan 6 Pemegang program UKM di Puskesmas, anggota Ikatan Fisioterapi Indonesia wilayah DKI Jakarta dan 3 Kepala Puskesmas yang terdapat layanan fisioterapi di Puskesmas wilayah DKI Jakarta. Penelitian ini telah lulus kaji etik melalui Komisi Etik Riset dan Pengabdian Kesehatan Masyarakat Fakultas Kesehatan Masyarakat Universitas Indonesia dengan nomor etik 328/UN.2. F10/PPM.00.02/2019.

\section{Hasil dan Pembahasan \\ 3.1 Kebijakan}

Dalam pelayanannya setiap kebijakan fisioterapi di Puskesmas mengacu pada Permenkes Nomor 75 Tahun 2014 tentang Pusat Kesehatan Masyarakat untuk Layanan Upaya Kesehatan Masyarakat maupun Upaya Kesehatan Perorangan. Meskipun setiap Puskesmas mengacu pada kebijakan nasional tersebut, akan tetapi perlu adanya standar layanan masing-masing yang disesuaikan dengan kondisi dan kebutuhan Puskesmas terkait. Hal tersebut sesuai dengan kutipan berikut:

“...kalau untuk kebijakan sendiri sih belum ada, paling yaa sesuai di permenkes 75 tahun 2015 yang UKM esensial dan pengembangan, dan memang kan 
ada kebijakan permenkes, pergub sampai ke interen Fisioterapi." (Informan Ka.Satpel UKM PKC Jatinegara)

Kebijakan terkait layanan fisioterapi di Puskesmas sudah diatur dalam Keputusan Kepala Puskesmas Kecamatan Koja sedangkan untuk SOP nya terdapat pada Keputusan Kepala Puskesmas tentang Standar Layanan Klinis yaitu di Puskesmas Kecamatan Koja, Puskesmas Kecamatan Kebayoran Lama, dan Puskesmas Kecamatan Matraman. Hal tersebut sesuai dengan kutipan berikut:

“....selain itu kita ada kebijakan yaa kita punya SK kepala Puskes sendiri disini tentang pengelolaan UKM sama UKP masing-masing, yaa itu karna di SK itu kan sudah disesuaikan dengan masingmasing program tadi sesuai dengan PMK 75 lagi dan bukan dengan orang fisioterapis masuk ukm itu tapi di UKP.” (Informan Ka.Satpel UKM PKC Koja)

Berdasarkan hasil wawancara dengan tenaga fisioterapis, pemegang program dan kepala Puskesmas, didapatkan bahwa pelayanan fisioterapi termasuk kedalam pelayanan kesehatan perseorang (UKP) yang fokusnya memberikan pelayanan kesehatan kepada masyarakat dengan rujukan dokter. Selain itu untuk terlibat dengan Upaya Kesehatan Masyarakat (UKM) tergantung dengan kewenangan dan kebijakan dari pemegang program tersebut karena tidak ada batasan dan regulasi yang mengatur tenaga apa saja yang dapat dan tidak dapat terlibat dengan Program di Upaya Kesehatan Masyarakat.

Meskipun telah ada kebijakan nasional yaitu Permenkes Nomor 65 Tahun 2015 tentang Standar Pelayanan Fisioterapi, tetapi peran dari Kebijakan Internal Fisioterapi masih belum dapat memenuhi kualifikasi dari masuknya tenaga fisioterapis dalam kegiatan Upaya Kesehatan Masyarakat (UKM). Karena sebagian besar pemegang program dan pimpinan Puskesmas beranggapan bahwa layanan fisioterapi merupakan pelayanan atau jasa untuk memberikan penyembuhan dan pemulihan pada perseorangan yang bersifat kuratif dan rehabilitatif, sedangkan untuk penyuluhan dan pencegahan ke masyarakat tidak dapat dilakukan oleh tenaga fisioterapis yang bertugas di Puskesmas. Fisioterapis menurut Maharaj, Chung, \& Cott tahun (2018) sebagai profesi kesehatan dapat memberikan gerakan latihan dan resep untuk aktivitas fisik kepada masyarakat serta dapat signifikan berkontribusi mengurangi beban dari morbiditas dan mortalitas penyakit tidak menular (7).

\subsection{SDM Fisioterapi}

Ketersediaan SDM Fisioterapis di Puskesmas wilayah DKI Jakarta masih sangat kurang, dari keseluruhan Puskesmas yang ada hanya terdapat 7 (tujuh) orang tenaga pelaksana Fisioterapis tersebar di 6 (enam) Puskesmas Kecamatan dari 44 Puskesmas Kecamatan yang ada di wilayah DKI Jakarta. Hal ini mengakibatkan sering tutupnya poli saat petugas tersebut akan cuti, izin, ataupun sakit sehingga pelayanan Fisioterapi menjadi sangat terbatas. Hal tersebut sesuai dengan kutipan berikut:

"karna kan cuma 1 yaa dia ga bisa kemana-kemana di pelayanan aja kalo fisio karna kan tupoksi nya di ukp. ” (Informan Ka.Satpel UKM PKC Koja)

SDM Fisioterapis hanya melakukan kegiatan dalam gedung ataupun pengobatan juga melakukan tugas pokok dan fungsi nya diluar pemberian sebagai layanan fisioterapi. Seperti tenaga fisioterapis di Puskesmas Kec. Kebayoran lama yang bertanggung jawab terhadap Alat Kesehatan mulai dari perencanaan, pelaporan tindakan sampai pendistribusian alat. Lain hal dengan Puskesmas Kec. Jatinegara tenaga fisioterapis melakukan tugasnya juga sebagai penanggungjawab Alat Tulis Kantor (ATK) di wilayah Puskesmas. Begitu juga dengan tenaga fisioterapis di Puskesmas Kec. Pasar Minggu yang melakukan tugas pada bagian mutu sebagai dokumen kontrol, pelayanan pelanggan, audit internal. Selain itu tenaga fisioterapis di Puskesmas Kec. Koja melakukan kegiatan lain seperti input haji, audit rekam medik dan audit indikator mutu.

Berdasarkan hasil wawancara dengan para sumber, adanya tugas lain di luar tugas pokoknya sebagai tenaga fisioterapis memang dapat menunjang kemampuan individu namun tidak dalam tugasnya sebagai tenaga kesehatan yang berada di Puskesmas. Peran sumber daya manusia fisioterapis yang bekerja di Puskesmas lebih banyak hanya melakukan tindakan penyembuhan perseorangan dengan pendekatan alat-alat berdasarkan rujukan dari dokter. Namun, didapatkan tiga dari enam Puskesmas yang ada pelayanan fisioterapi melakukan tindakan kesehatan perseorangan dan juga terlibat di Upaya Pelayanan Kesehatan Masyarakat.

Pada era Jaminan Kesehatan Nasional ini layanan fisioterapi merupakan pelayanan spesialistik yang masuk dalam pelayanan penunjang(8) maka dari itu dukungan dari kebijakan Puskesmas sendiri juga membuat pelayanan fisioterapi berfokus melakukan pelayanan pengobatan dengan upaya kuratif di Puskesmas bukan untuk pelayanan pada penyuluhan dan pencegahan kepada masyarakat di luar gedung Puskesmas. Tugas pokok dan fungsi dari layanan fisioterapi di Puskesmas yaitu melakukan tindakan fisioterapi yang utama dalam memberikan pelayanan kesehatan secara promotif dan preventif tanpa mengesampingkan upaya kuratif dan rehabilitatif. (4) Dalam memberikan pelayanan kuratif, fisioterapis diberikan wewenang untuk melakukan anamnesa pemeriksaan fisioterapi, membuat catatan medik, serta memberikan penyuluhan yang dapat bersifat promotif dan preventif di dalam gedung Puskesmas.

Fungsi fisioterapis dalam upaya promotif dan preventif terlihat dari Puskesmas Kec. Matraman yang terlibat dalam pelayanan Upaya Berhenti Merokok, sedangkan Puskesmas Kec. Jatinegara terlibat dalam Upaya Kesehatan Sekolah dan Puskesmas Kec. Pasar Minggu terlibat dalam Poli Haji, Poli PTM, dan Poli Lansia. Namun peran tersebut dirasa belum mencukupi karena belum meratanya SDM kesehatan di fasilitas kesehatan tingkat pertama di Indonesia. (9) Selain melakukan tindakan layanan klinis di Puskesmas, petugas Fisioterapis juga diberikan tugas untuk melakukan tupoksi lain didalam gedung. Namun lebih banyaknya tugas non klinis membuat kurangnya kegiatan yang dapat dilakukan oleh fisioterapis di luar gedung atau di masyarakat. Menurut penelitian Halimuddin 
(2015) (10) jika pegawai melaksanakan tugas tambahan diluar dari tupoksinya cenderung akan kurang efektif sehingga hal tersebut akan mempengaruhi kinerja pegawai.

\subsection{Kompetensi Fisioterapi}

Berdasarkan Permenkes Nomor 80 tahun 2013 tentang Standar Praktik Fisioterapi, sebagai tenaga fisioterapis yang bertugas di Puskesmas sekurangkurangnya harus memiliki Surat Tanda Registrasi (STR), Surat Izin Praktek Fisioterapi (SIPF) dan minimal pendidikan D3 Fisioterapi. (11) Untuk mendukung pelayanan promotif dan preventif di Puskesmas, tenaga fisioterapis perlu memiliki kompetensi dalam berkomunikasi yang efektif salah satunya dengan mengikuti pelatihan sebagai promotor kesehatan, meskipun pelatihan tersebut jarang melibatkan tenaga fisioterapis di Puskesmas. Hal tersebut sesuai dengan kutipan berikut:

"STR dan SIPF wajib punya kalau di puskes yaa.. dan ini karna tidak terjadi juga ada pelatihan untuk melibatkan fisioterapi di program ukm, kalopun ada fisio harus bisa promkes." (informan Ka.Satpel UKM PKC Pancoran)

"jadi kalo program ukm tadi bagaimana kita mencegah, intinya mencegah, promosi tidak rehabilitasi, bagaimana memberikan promosi, komunikasi yg baik, ke masyarakat. Kalo orang yang ke puskesmas kita mengharapkan orang-orang yg sehat juga datang." (informan Ka. Satpel UKM Pasar Minggu)

Berdasarkan hasil wawancara dengan tenaga fisioterapis maupun penanggung jawab program UKM, belum ada pelatihan khusus untuk fisioterapis, namun diwajibkan bagi seluruh tenaga kesehatan yang bertugas di Puskesmas agar dapat melakukan kegiatan promosi kesehatan mulai dari penyuluhan, pencegahan dan berkomunikasi dengan masyarakat di wilayah kerja Puskesmas tersebut. Berbeda dengan pelayanan di rumah sakit, tenaga fisioterapis di Puskesmas dituntut untuk dapat memberikan penyuluhan dan melakukan kolaborasi dalam melaksanakan kegiatan yang bersifat promotif dan preventif. Untuk dapat melakukan penyuluhan kesehatan, tenaga fisioterapis harus memiliki kemampuan dan kompetensi untuk memberikan upaya seperti Promosi Kesehatan. (12)

Adanya pelatihan dan pengembangan kompetensi dibutuhkan untuk mengasah kemampuan Fisioterapis dalam membuat suatu kegiatan pelayanan kesehatan masyarakat yang berkolaborasi dengan tenaga kesehatan lain pada program di Puskesmas. Menurut tenaga fisioterapis yang bertugas di Puskesmas perlu adanya pelatihan khusus dalam upaya mempromosikan kesehatan dan mencegah penyakit dengan cakupan yang lebih luas. Keterampilan yang dimiliki oleh tenaga kesehatan di Puskesmas dapat berpengaruh terhadap pelatihan yang di dapatkan. (13)

\subsection{Health Promotion (Promosi Kesehatan)}

Selain melakukan tindakan yang bersifat pengobatan, fisioterapis di Puskesmas dapat memiliki peran untuk melakukan upaya promosi kesehatan di dalam maupun di luar gedung. Dalam melakukan upaya promosi kesehatan di Puskesmas, tenaga fisioterapis membuat perencanaan kegiatan layanan fisioterapi dengan bekerjasama pada program-program yang terdapat di Puskesmas. Hal tersebut sesuai dengan kutipan berikut:

“....yaaa fisioterapis harus jadi promotor terutama mereka harus menguasai dan juga harus sebagai promosi kesehatan, mereka juga harus bisa edukasi ke masyarakat, karna kita rencana nya mau ngajak mereka untuk lebih ke arah promosi dan peragaan kesehatan ke anak-anak sekolah." (Informan Ka.Satpel UKM Jatinegara)

Berdasarkan hasil wawancara didapatkan layanan fisioterapi di Puskesmas Kec. Jatinegara melakukan promosi kesehatan di lingkungan sekolah bekerjasama dengan pemegang program Upaya Kesehatan Sekolah (UKS) untuk memberikan penyuluhan berupa peragaan cara duduk, memberikan edukasi pada anak untuk melakukan aktivitas fisik yang sesuai dengan tingkat usia yang baik dan terukur. Hal tersebut berdasarkan kutipan berikut:

“....waktu itu saya ngajuin buat kerjasama, nah disitu kesempatan saya untuk jabarin lah kompetensi yang dimiliki fisio, dan jelasin kita bisa apa, yaa minimal komunikasi dulu sih ke pemegang program ukm nya, baru mereka yang nentuin kita bisa dimana nih. Kebetulan memang peluangnya disini buat fisio sih di anak-anak sekolah jadi ikutlah sama program UKS nya.” (Informan FT PKC Jatinegara)

Pada Kesehatan Haji, layanan fisioterapi di Puskesmas Kec. Pasar Minggu bekerjasama dengan pemegang program Kesehatan Haji untuk memberikan penyuluhan kesehatan berupa skrining keseimbangan, latihan fisik dan senam yang aman untuk menjaga kebugaran para calon jama'ah Haji. Berdasarkan hasil wawancara dengan tenaga fisioterapis dan pemegang program di UKM, pada Layanan Kesehatan haji di Puskesmas Kec. Pasar Minggu, Fisioterapis berperan utama dalam memberikan edukasi kebugaran serta mengontrol agar para jama'ah haji yang sudah lansia tidak mengalami gangguan gerak dan fungsi tubuh selama ibadah.

Sejalan dengan penelitian Wahyuni (2006) bahwa layanan Fisioterapi memiliki peranan penting pada kesegaran dan kebugaran jasmani, karena diketahui bahwa $70 \%$ kegiatan haji merupakan aktivitas fisik. (14) Menurut penelitian (Ningsih, 2005) dengan memberikan senam haji, dapat berpengaruh pada peningkatan daya tahan jantung paru yang dilakukan pada para calon jama'ah haji yang tidak berisiko tinggi. (15)

Berdasarkan hasil wawancara dengan tenaga fisioterapis dan pemegang program di Puskesmas Kec. Matraman, layanan fisioterapi berkontribusi dengan pemegang program Upaya Berhenti Merokok (UBM) untuk melakukan penyuluhan kesehatan. Terlibatnya fisioterapis pada program UBM diharapkan agar masyarakat yang berupaya untuk berhenti merokok dapat 
mengembalikan kebugaran dan kesehatan paru nya. Namun masih dibutuhan pelatihan tambahan pada Fisioterapis untuk memberikan intervensi kepada pasien maupun klien dalam memberikan dosis untuk kegiatan fisik untuk mempromosikan dan mendukung upaya berhenti merokok. (16)

Namun berbeda dengan layanan fisioterapi di Puskesmas Kec. Koja dalam memberikan upaya promosi kesehatan kepada masyarakat melalui media cetak yaitu membuat Leaflet atau yang biasa disebut selembaran kertas yang berisi tulisan mengenai layanan fisioterapi dan manfaat fisioterapi berupa gambar gerakan latihan aktif dengan kalimat-kalimat singkat, diisi dengan gambar yang sederhana dan mudah dimengerti. (17) Media promosi kesehatan merupakan alat yang digunakan untuk menyampaikan materi tentang kesehatan kepada masyarakat dengan mempertimbangkan sasaran dari promosi kesehatan (18)

Diketahui peran fisioterapis dalam upaya promosi kesehatan oleh sebagian besar masyarakat berdasarkan persepsinya, didapatkan bahwa fisioterapis mampu memberikan promosi kesehatan kepada masyarakat sebagai panutan untuk melakukan aktivitas fisik rutin sebesar $(83.4 \%)$, mempertahankan berat badan yang sehat sebesar $(71.7 \%)$, dan tindakan untuk berhenti merokok sebesar (63.9\%). (6)

\subsection{Sepesific Protection (Perlindungan Khusus)}

Dalam melakukan upaya perlindungan khusus layanan fisioterapi juga bekerjasama dengan program di UKM untuk melakukan tindakan pencegahan khusus agar masyarakat tidak terkena penyakit, bahkan yang sudah terkena penyakit juga dapat diberikan perlindungan khusus tanpa menggunakan atau mengonsumsi obat. Hal tersebut dilakukan oleh layanan fisioterapi di Puskesmas Kec. Pasar Minggu dengan berkolaborasi pada program lansia, dan pelayanan penyakit tidak menular (PTM) dengan memberikan senam rutin setiap bulannya dan dilakukan setiap minggu. Hal tersebut sesuai dengan kutipan berikut:

"yaa kalo promotif kan promosiin fisioterapi, nah kalo preventif untuk tahap ini sih hampir sama, paling untuk lansia, DM kita ada senam prolanis, senam DM rutin tiap bulan." (Informan FT PKC Pasar Minggu)

Berdasarkan hasil wawancara dengan tenaga fisioterapis yang bekerja di Puskesmas wilayah DKI Jakarta untuk pasien dengan indikasi respirasi akan diberikan terapi inhalasi. Pada alat tersebut harus dengan menggunakan masker nebulizer pada pasien yaitu satu orang satu masker dan tidak diperbolehkan menggunakan masker yang sudah digunakan oleh orang lain. Selain penggunaan masker inhalasi, fisioterapis juga melakukan perlindungan khusus di Layanan dengan menggunakan APD (Alat Pelindung Diri), dan juga masker bedah. Hal tersebut sesuai dengan kutipan berikut:

"untuk di Poli kita kadang suka pake APD dan

hand scoon, trus sama masker buat nebu satu orang satu, sama kalo pasien beresiko paling kita kasih masker wajah." (Informan FT PKC Koja)
Menurut Permenkes Nomor 27 tahun 2017 memberikan pengetahuan kepada tenaga kesehatan tentang cara menyimpan, membuang, menangani dan menggunakan kembali peralatan kesehatan dengan aman merupakan hal yang penting untuk mencegah terjadinya penyakit menular. Hal tersebut dilakukan agar mengurangi resiko pada penularan penyakit. Pada layanan fisioterapi di Puskesmas juga diberikan edukasi dan latihan terkait perlindungan khusus untuk mengurangi resiko jatuh pada lansia khususnya dengan memberikan senam prolanis, dan juga senam kebugaran hal tersebut sejalan dengan penelitian Supriyono (2015) (19) dan juga pada penderita diabetes agar dapat meningkatkan aktivitas fisik dan mengurangi kadar gula dalam tubuh (20) yaitu dengan diberikan senam diabetes tiap minggu di Puskesmas.

\subsection{Early Diagnosis and Prompt Treatment (Deteksi Dini dan Perawatan yang Tepat)}

Pada upaya deteksi dini dan perawatan yang tepat layanan fisioterapi melakukan peran nya untuk mencegah terjadinya kecacatan dan komplikasi pada pasien maupun masyarakat. Layanan fisioterapi melakukan peran tersebut sebagai langkah awal untuk menentukan program tindakan yang akan diberikan oleh fisioterapis di Puskesmas. Peran Fisioterapis dalam mengelola deteksi dini dan perawatan yang tepat yaitu dengan melakukan anamnesa kembali pasien rujukan dokter guna menentukan tindakan yang tepat dan biasanya dilakukan 2-3 kali kunjungan untuk dapat melihat kurangnya keluhan pasien yang datang. Jika dilihat dan diperiksa kembali tidak terjadi pengurangan keluhan pada pasien maka akan mendiskusikannya kembali dengan dokter pengirim dan diberikan evaluasi, hal tersebut sesuai dengan kutipan berikut:

“....kalo kita sih di pelayanan ada SOAP, untuk anamnesa pasien diasesmen lagi keluhan nya apa untuk tau posisi persisnya, juga tanya dia pekerjaan nya apa karna nanti ngaruh ke gerakan dia, trus paling kita evaluasi karna kita juga kan udah pake epus ya diliat dari kedatangannya aja sih bisa." (Informan FT PKC Keb.Lama)

Berdasarkan hasil wawancara dengan tenaga fisioterapis dan pemegeang program di Puskesmas, layanan fisioterapi untuk melakukan kegiatan skrining harus bekerjasama dengan pemegang program di Puskesmas. Layanan fisioterapi di Puskesmas Kec. Pasar Minggu melakukan pemeriksaan dan skrining test keseimbangan dan pengukuran kebugaran pada Calon Jama'ah Haji bekerjasama dengan Poli Haji dan Kesehatan Olah Raga. Dengan melakukan skrining kebugaran pada jamaah haji dengan metode tertentu seperti rockport yaitu untuk mengukur kebugaran jantung dan paru, hal tersebut sejalan dengan penelitian Budiman,et al (2017) (21).

Sedangkan di dalam pelayanan kesehatan perseorangan layanan fisioterapi yang hanya memberikan perawatan di dalam gedung berintegrasi dengan poli pelayanan kesehatan sesuai dengan kebijakan di Puskesmas. Fisioterapi memiliki peran khusus untuk mencegah terjadinya gangguan gerak dan fungsi yang 
menyebabkan disabilitas yang berkepanjangan (22).

\subsection{Disability Limitation (Pembatasan Kecacatan)}

Berdasarkan perannya dalam mengelola upaya preventif pada pembatasan kecacatan, layanan fisioterapi di Puskesmas melakukan upaya nya agar pasien yang sudah dilakukan perawatan tidak mengalami kecacatan maupun keterbatasan gerak dan fungsi tubuh. Pada poli fisioterapi di Puskesmas pembatasan kecacatan dilakukan pada pasien dari rujukan poli umum dengan memberikan modalitas fisioterapi agar tidak terjadi komplikasi dan gangguan gerak. Selain dilakukan di dalam poli fisioterapi, upaya pembatasan kecacatan diberikan juga untuk latihan dirumah, agar dapat mengurangi kondisi sakit dan keluhan pasien agar tetap aktif dalam beraktivitas dan tidak timbul kecacatan.

“...y yaa itu pasti kita asesmen dulu diawal kalo kita tau keterbatasan nya dulu kemampuannya sampe mana kalo misalnya ternyata harus ditindak lebih lanjut dan area nya yg luas kita harus merujuk ke rumah sakit gitu, tapi kalo selama masih bisa kita handle dengan area dan alat yg ada disini kita lakukan disini." (Informan FT PKC Matraman)

Dalam upaya Pembatasan Kecacatan layanan fisioterapi sangat berperan untuk mengatasi masalah ruang lingkup sendi nya yang mulai terbatas, mengurangi keluhan dengan menggunakan metode intervensi fisioterapi dan ditunjang dengan modalitas fisioterapi di Puskesmas. (4) Berdasarkan hasil wawancara dengan tenaga fisioterapis yang bertugas di Puskesmas, rata-rata pasien yang datang ke poli fisioterapi merupakan pasien rujukan, dan untuk mengevaluasi tidak adanya kecacatan maupun keluhan lain, Fisioterapis selalu mencatat setiap tindakan di dalam rekam medis dan juga mengomunikasikannya dengan dokter pengirim.

\subsection{Rehabilitation (Rehabilitasi)}

Upaya Rehabilitasi yang dimaksud disini adalah rehabilitasi pada lingkup pencegahan di layanan fisioterapi di Puskesmas wilayah DKI Jakarta agar pasien tidak semakin parah dan diharapkan dapat kembali ke aktivitasnya semula. Dalam upaya rehabilitasi dapat mencegah masyarakat yang sudah mengalami keluhan agar tidak terkena resiko yang berulang. Hal tersebut sesuai dengan kutipan berikut:

"upaya rehabilitasi ini kalo di Puskesmas upaya pencegahan ya supaya pasien tidak jatuh pada saat jalan misalnya, kayak lansia kalo kita latih untuk mencegah agar tidak jatuh dan kena penyakit yang berulang. ” (Informan Ka.IFI DKI Jakarta)

Dalam perannya di pelayanan kesehatan perseorangan, layanan fisioterapi di Puskesmas melakukan kerjasama dengan dokter di poli umum dan perawat nya. Jika ada indikasi lain juga dikomunikasikan kembali dengan dokter pengirimnya lalu dapat di rekomendasikan ke poli lain sesuai dengan keluhannya. Dalam upaya mengembangkan pelayanan fisioterapi sebagai pelayanan rehabilitasi di Puskesmas, tenaga fisioterapis dapat melakukan perannya untuk memberikan masukan kepada pimpinan Puskesmas agar pelayanan tersebut dapat lebih maksimal untuk melayani masyarakat di fasilitas kesehatan tingkat pertama. Tenaga fisioterapis dapat memberikan masukannya saat rapat internal untuk penambahan alat modalitas Fisioterapi. Hal tersebut sesuai dengan kutipan berikut:

"kemarin paling saya minta tambahan alat-alat aja buat ngebantu di pelayanan." (Informan FT PKC Pancoran)

Berdasarkan hasil wawancara tersebut diharapkan dapat meningkatkan pelayanan Fisioterapi dan juga mengurangi rujukan ke fasilitas kesehatan tingkat lanjut yang disebabkan karena keterbatasan alat maupun ruangan di Layanan Fisioterapi pada Puskesmas wilayah DKI Jakarta.

Pada level rehabilitation, layanan fisioterapi mengembangkan penyuluhan dan usaha-usaha lanjutan yang harus dilakukan oleh orang yang berada di pemulihan kesehatan agar dapat juga dilakukan di rumah yaitu memberikan edukasi bagi masyarakat atau klien mengenai hidup dengan alat bantu gerak, juga melibatkan keluarga dalam setiap penanganan bagi masyarakat, dan membantu mengembalikan kepercayaan diri klien agar dapat kembali beraktivitas di masyarakat dengan optimal. Hal tersebut secara bersamaan mengurangi tingkat disabilitas, perawatan inap, dan biaya perawatan kesehatan (23).

\section{Kesimpulan}

Dari upaya pelayanan kesehatan yang sudah dilakukan pada layanan fisioterapi di Puskesmas wilayah DKI Jakarta dapat di lihat bahwa peran layanan fisioterapi berdasarkan kebijakannya adalah melakukan pelayanan kesehatan perseorangan di UKP. Adanya upaya pelayanan kesehatan masyarakat oleh layanan fisioterapi di Puskesmas dapat dilakukan berdasarkan kebijakan dan wewenang penanggung jawab pemegang program yang melibatkan tenaga fisioterapis. Namun saat ini masih minimnya wadah kebijakan untuk layanan fisioterapi dalam memberikan upaya kesehatan masyarakat dan masih dominannya melakukan upaya kesehatan perseorangan di Puskesmas dan kurangnya SDM fisioterapis di Puskesmas mengurangi peran layanan Fisioterapi di Puskesmas untuk dapat memberikan pelayanan kesehatan Masyarakat.

\section{REFERENSI}

[1]. Permenkes. Peraturan Menteri Kesehatan Nomor 75 tahun 2014 tentang Pusat Kesehatan Masyarakat. 2014;

[2]. Kementrian kesehatan RI. Hasil utama riskesdas 2018. 2018;61.

[3]. Ontario Physiotherapy Association. Physiotherapy in Primary Health Care. Physiother Prim Heal Care [Internet]. 2017;1(October):1-13. Available from: https://opa.on.ca/wpcontent/uploads/Physiotherapists-PrimaryHealth-Care.pdf 
[4]. Permenkes RI. Peraturan Menteri Kesehatan Republik Indonesia Nomor 65 Tahun 2015 tentang Standar Pelayanan Fisioterapi. 2015;

[5]. Fai'zah N, Lestari US. Peran promosi kesehatan terhadap tingkat motivasi pasien mendapatkan layanan fisioterapi di puskesmas Bantimurung. Ber Kedokt Masy (BKM J Community Med Public Heal. 2017;293-8.

[6]. Black B, Ingman M, Janes J. Promotion as Perceived by the Patient: Descriptive Survey. Am Phys Ther Assoc. 2016;96(10):1588-96.

[7]. Maharaj S, Chung C, Dhugge I, Gayevski M, Muradyan A, McLeod KE, et al. Integrating physiotherapists into primary health care organizations: The physiotherapists' perspective. Physiother Canada. 2018;70(2):188-95.

[8]. Yunita S. Pelayanan Fisioterapi pada Era JKN di RSJD DR.RM. Soedjarwadi Klaten. Public Heal / Hosp Care Manag Hosp PELAYANAN. 2018;

[9]. Mujiati M, Yuniar Y. Ketersediaan Sumber Daya Manusia Kesehatan pada Fasilitas Kesehatan Tingkat Pertama dalam Era Jaminan Kesehatan Nasional di Delapan Kabupaten-Kota di Indonesia. Media Penelit dan Pengemb Kesehat. 2017;26(4):201-10.

[10]. Halimuddin. Pengaruh Beban Kerja, Lingkungan Kerja Dan Disiplin Kerjaterhadap Kinerja Pegawai (Studi Balai Penelitian dan Pengembangan Pengendalian Penyakit Bersumber Binatang Donggala, Kementerian Kesehatan RI). e-jurnal katalogis. 2015;3(11):6172.

[11]. Permenkes. Peraturan Menteri Kesehatan Republik Indonesia Nomor 80 tahun 2013 Tentang Penyelenggaraan Pekerjaan dan Praktik Fisioterapis. 2013. p. 1-13.

[12]. Abaraogu UO, Edeonuh JC, Frantz J. Promoting physical activity and exercise in daily practice: Current practices, barriers, and training needs of physiotherapists in eastern Nigeria. Physiother Canada. 2016;68(1):37-45.

[13]. Putri SMD. Pengaruh pelatihan orientasi keluarga sehat untuk mendukung program Indonesia sehat di kabupaten Lumajang tahun 2018. Ber Kedokt Masy. 2018;4.

[14]. Wahyuni. Fisioterapi haji meningkatkan kesegaran jasmani. SUHUF. 2006;28(01):27-38.

[15]. Ningsih IS. Pengaruh Latihan Senam Haji Terhadap Peningkatan Daya Tahan Jantung Paru Pada Calon Jamaah Haji Non Resiko Tinggi. 2005;5(2):45-50.

[16]. Bezner JR. Perspective Promoting Health and Wellness: Implications for Physical Therapist Practice. ptjournal.apta.org. 2015;95(10):143344.

[17]. Haryani S, Sahar J, Sukihananto S. Penyuluhan Kesehatan Langsung dan melalui Media Massa Berpengaruh terhadap Perawatan Hipertensi pada Usia Dewasa Di Kota Depok. J Keperawatan Indones. 2016;19(3):161-8.
[18]. Notoatmodjo S. Metodologi Penelitian Kesehatan: Edisi Revisi. Jakarta: Rineka Cipta; 2015.

[19]. Supriyono E. Aktivitas Fisik Keseimbangan Guna Mengurangi Resiko Jatuh Pada Lansia. J Olahraga Prestasi. 2015;11(2):91-5.

[20]. Colberg SR, Sigal RJ, Yardley JE, Riddell MC, Dunstan DW, Dempsey PC, et al. Physical activity/exercise and diabetes: A position statement of the American Diabetes Association. Diabetes Care. 2016;39(11):2065-79.

[21]. Budiman I, Aprijana I, Iskandar D. Penggunaan Tes Lapangan 1,6 Km Metoda Rockport Untuk Pengukuran Kebugaran Jantung-Paru Dengan Baku Emas Treadmill Metoda Bruce. J Sains Keolahragaan dan Kesehat. 2017;2(2):38-41.

[22]. Frantz JM, Ngambare R. Physical Activity and Health Promotion Strategies Among Physiotherapists in Rwanda. Afr Health Sci. 2013;13(1):17-23.

[23]. Gustavson AM, Falvey JR, Jankowski CM, Stevens-Lapsley JE. Public Health Impact of Frailty: Role of Physical Therapists. J frailty \&amp; aging. 2017;6(1):2 